\title{
Isolated Cervical Dystonia: Management and Barriers to Care
}

\author{
Melanie Leigh Supnet ${ }^{1 *}$, Patrick Acuna ${ }^{1}$, Samuel J. Carr ${ }^{1}$, Jan Kristoper de Guzman ${ }^{2}$, \\ Xena Al Qahtani ${ }^{1}$, Trisha Multhaupt-Buell ${ }^{1}$, Taylor Francoeur ${ }^{1}$, Gabrielle E. Aldykiewicz' ${ }^{1}$, \\ Priyanka R. Alluri ${ }^{1}$, Lindsey Campion ${ }^{1}$, Lisa Paul ${ }^{1}$, Laurie Ozelius ${ }^{1}$, Ellen B. Penney ${ }^{1}$, \\ Christopher D. Stephen ${ }^{1}$, Marisela Dy-Hollins ${ }^{1}$ and Nutan Sharma ${ }^{1}$ \\ ${ }^{1}$ Department of Neurology, Massachusetts General Hospital and Harvard Medical School, Boston, MA, United States, \\ ${ }^{2}$ Department of Neurology, Jose R. Reyes Memorial Medical Center, Manila, Philippines
}

\section{OPEN ACCESS}

Edited by:

Salvatore Galati,

Neurocenter of Southern

Switzerland, Switzerland

Reviewed by:

Leonardo Almeida,

University of Florida, United States

Kathryn Peall,

Cardiff University, United Kingdom

Patricia Krause,

Charité - Universitätsmedizin

Berlin, Germany

*Correspondence:

Melanie Leigh Supnet

msupnet@mgh.harvard.edu

Specialty section: This article was submitted to Movement Disorders, a section of the journal

Frontiers in Neurology

Received: 04 August 2020 Accepted: 20 October 2020 Published: 27 November 2020

Citation:

Supnet ML, Acuna P, Carr SJ, Kristoper de Guzman J, Al Qahtani X,

Multhaupt-Buell T, Francoeur T,

Aldykiewicz GE, Alluri PR, Campion L,

Paul L, Ozelius L, Penney EB,

Stephen CD, Dy-Hollins M and

Sharma N (2020) Isolated Cervical

Dystonia: Management and Barriers

to Care. Front. Neurol. 11:591418.

doi: 10.3389/fneur.2020.591418
Background: Cervical dystonia (CD) is a rare disorder, and health care providers might be unfamiliar with its presentation, thus leading to delay in the initial diagnosis. The lack of awareness displays the need to highlight the clinical features and treatment in cervical dystonia. In our cohort, we have identified an earlier age of onset in men, despite an overall preponderance of affected women.

Objective: We aim to identify the prevalence, age of onset, spread, and treatment modalities of $\mathrm{CD}$ in the population. We also highlight the barriers which patients encounter related to diagnosis, follow-up, and treatment.

Methods: We reviewed 149 CD patients who attended specialized Dystonia Clinics over a 14-year period. Dystonia severity was rated using the Burke-Fahn-Marsden (BFM), Tsui, and Toronto Western Spasmodic Torticollis Rating Scales (TWSTRS). Mood and quality of life were assessed using Beck Depression Inventory (BDI), Beck Anxiety Inventory (BAI), and 36-Item Short Form Health Survey (SF-36).

Results: CD patients were majority White (91.3\%) and more commonly female (75.8\%). Men had an earlier median age of onset, 40.5 years $(p=0.044)$. BAl revealed a mean score of $7.2( \pm 6.4, n=50)$ indicating minimal anxiety while BDI revealed a mean score of $7.30( \pm 7.6, n=50)$ indicating minimal depression. The only SF-36 subscales associated with CD severity were physical functioning $(p=0.040)$ pain $(p=0.008)$ and general health $(p=0.014)$.

Conclusion: There appear to be gender differences in both the prevalence and age of onset of the disease. There was a 3-fold higher incidence in women than in men. CD patients of both sexes experience barriers to care, which can be reflected in their quality of life and time-to-diagnosis. In addition, males were less likely to experience an objective benefit with botulinum toxin treatment and more likely to discontinue care. Greater awareness of $C D$ by health care providers is important to reduce the time-to-diagnosis.

Keywords: cervical dystonia, movement disorders, treatment, barriers to care, clinical features 


\section{INTRODUCTION}

Isolated cervical dystonia (CD) is a common subtype of dystonia which involves abnormal neck movement, is frequently associated with pain, can be debilitating $(1,2)$, and has an estimated prevalence of 3-9 per 100,000 (3-6). Isolated CD is a rare condition, with the greatest incidence in White females and a mean age of onset between 45 and 50 years of age, and where the majority of patients do not have spread to other body parts $(5,7-10)$. There is a growing body of literature on the non-motor features of $\mathrm{CD}$, including executive dysfunction, depression, anxiety, pain, and increased disability, decreased quality of life $(7,11-13)$. Those with $C D$ display a high rate of depression or anxiety that has not previously correlated with dystonia severity (14). The main treatments in cervical dystonia are: botulinum toxin injections alone; botulinum toxin injections in combination with oral medication; and for refractory cases, deep brain stimulation (DBS) $(7,15)$.

Since cervical dystonia is a relatively rare disease, many physicians have little exposure while in training or clinical practice, which may lead to a delay in diagnosis and treatment. Delay in diagnosis of CD ranges from 3.75 to 6.8 years, with subjects having seen multiple providers prior to diagnosis (1618). The observed delay to diagnosis has been attributed, in part, to a lack of awareness within the healthcare profession (17). As CD can be treated, better recognition of the disorder would likely provide faster diagnosis and symptom relief to more individuals (16).

To date, there has been limited data on barriers to care for those with cervical dystonia. One study, involving $70 \mathrm{CD}$ patients at an academic movement disorders clinic in the United States, examined the treatment experiences and reasons for discontinued care (19). Thirty percent of patients discontinued their care, and the most cited reasons were a suboptimal response to or side effects from botulinum toxin, high cost of treatment, and excessive travel burden.

Here, we report on our findings in a CD cohort diagnosed and treated over 14 years at two large academic medical centers. We also report on unique features in our cohort, namely a marked gender difference in age of onset and the lack of significantly higher comorbid depression or anxiety than that found in the general population. This data adds to the existing literature on $\mathrm{CD}$ and points to greater heterogeneity in affected individuals than previously reported.

\section{METHODOLOGY}

\section{Subject Participation}

Subjects were recruited prospectively from the Dystonia Clinics at Massachusetts General Hospital and Brigham and Women's Hospital. We obtained coded data from 149 consecutive participants who were diagnosed with isolated $\mathrm{CD}$, with or without involvement of other body regions and enrolled in the Dystonia Partners Research Bank (DPRB) between January 2005 and December 2019. Twenty-five of the 149 subjects had previously enrolled in an observational study on dystonia and had additional motor scale scores. When available, we included prior motor scale scores for those subjects. All DPRB participants gave written informed consent for their data to be used in a natural history analysis. Our data analysis protocol was reviewed and approved by the Mass General Brigham Human Research Committee.

Diagnosis and confirmation that the subjects had isolated cervical dystonia, including a review of previous medication exposure, were determined according to published criteria (20, 21 ) by a neurologist trained in movement disorders (NS, MD, EP, CS). We assessed demographics, including time from symptom onset to diagnosis, family history, medical history, and prescribed medications. Subjects were assessed using a standardized movement disorder examination as described previously (22). Dystonia severity was rated in all patients using the Burke-Fahn-Marsden Motor Rating Scale (BFMMS) and in a subset of subjects with the Tsui Dystonia Scale and the Toronto Western Spasmodic Torticollis Rating Scale (TWSTRS). Followup examinations were completed in 98 participants, which all occurred at least 9 months after the first examination and around the time of medical appointments.

\section{Molecular Analysis}

DNA was extracted from white blood cells using the Purgene procedure (Gentra Systems, Minneapolis, MN). The samples were screened for presence of the TOR1A (DYT1) GAG deletion by PCR amplification as previously described (21).

\section{Socio-Economic Factors}

Insurance status was provided through medical record review and coded as either private or public, with the latter consisting of Medicare and Medicaid health insurance plans. Zip code, obtained at enrollment and/or medical record review, was used to calculate median household income using 2017 United States Government Census data [ref "American Fact Finder"]. The distance from the clinic was calculated by using the subject's address and the address of the clinic they attended.

\section{Mood and Quality of Life Assessment}

We obtained depressive and anxiety symptoms from the Beck Depression Inventory, 2nd edition (BDI) (23), and the Beck Anxiety Inventory (BAI) (24). The impact of CD on HealthRelated Quality of Life (HRQoL) was assessed using the 36-Item Short Form Health Survey (SF-36) (25). Fifty consecutive patients completed the BAI, BDI, and 49 completed the SF-36, which were given to participants and then returned by mail.

\section{Statistical Analysis}

We performed descriptive statistics. Categorical variables were compared with $\chi^{2}$ or Fisher's exact test. For continuous variables we used two-sample $t$-tests, and for highly skewed data the Wilcoxon rank sum test. We used Spearman's correlation coefficient to assess correlation in continuous variables. Changes in motor scores from baseline to their final scores were assessed using Wilcoxon signed-rank test for matched pairs. A one-sample $t$-test was used to compare the differences between the cohort's SF-36 subscores/general health and the corresponding Ware's normative values (26). Statistical significance was designated 
TABLE 1 | Clinical and demographic characteristics.

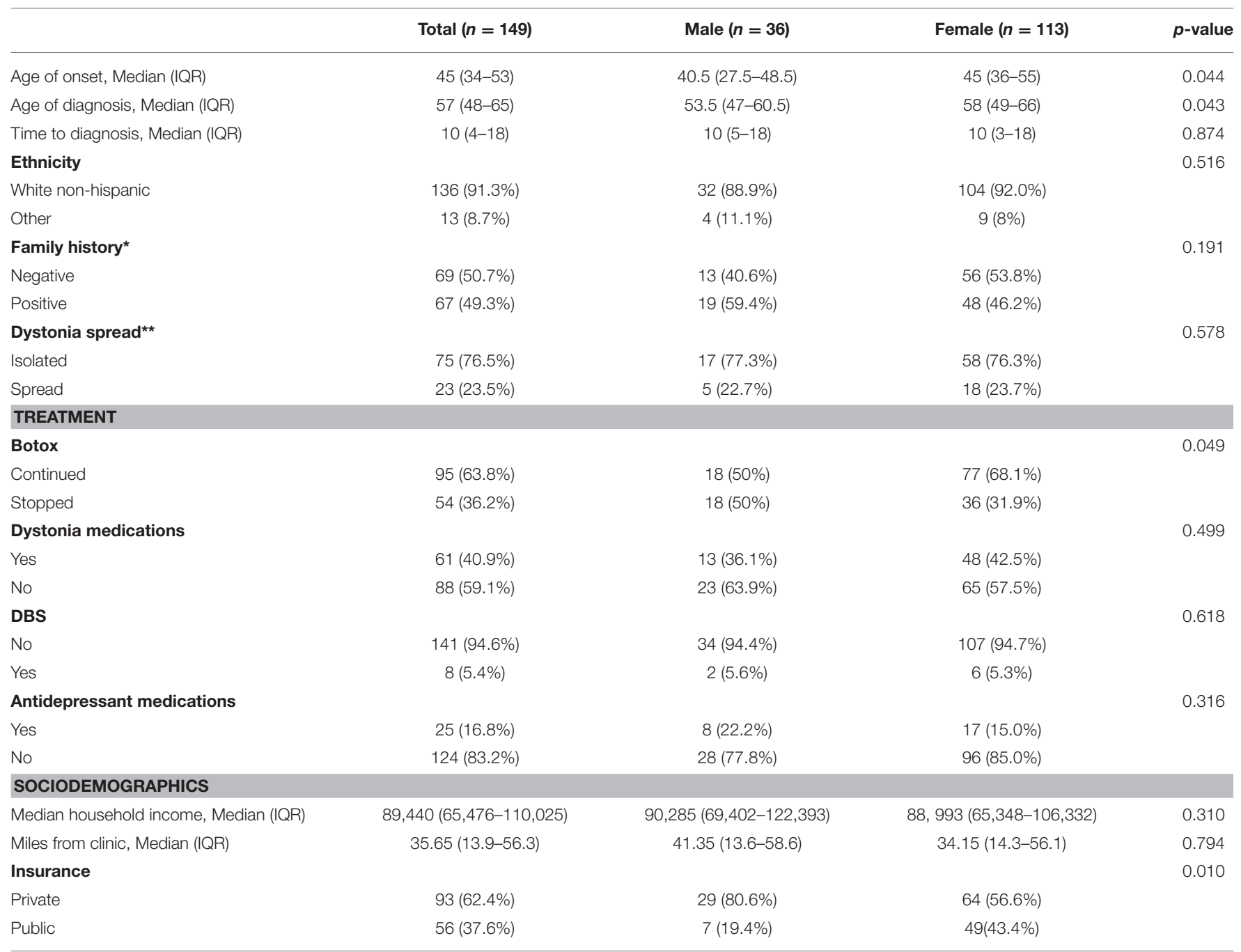

${ }^{*}$ Family History analyzed for positive/negative subjects only (136/149). Thirteen subjects had an unknown/possible history which researchers could not analyze effectively.

${ }^{\star \star}$ Dystonia spread available for subjects with $>1$ visit and followed for at least 0.75 years $(98 / 149)$.

by two-tailed $p<0.05$. Data was analyzed using STATA 15.1 (College Station, TX).

\section{RESULTS}

Data from a total of 149 subjects was used. Of these, 36 (24.2\%) were male and 113 (75.8\%) were female, as shown in Table 1. When analyzed by gender, the median age of onset of symptoms in the male cohort $(n=36)$ is 40.5 years $(\mathrm{IQR}=27.5-48.5)$, and the median age of onset in the female cohort $(n=113)$ is 45 years $(\mathrm{IQR}=36.0-55.0)$. Males had an earlier age of onset of symptoms compared to females $(p=0.044)$. Males also had an earlier age of diagnosis, 53.5 years (IQR $=47-60.5$ years), when compared to females, 58 years (IQR $=49-66$ years) $(p=0.043)$. Gender differences with respect to time-to-diagnosis were not significant $(p=0.874)$.
When compared to the overall race/ethnicity and gender data in the outpatient specialty care population at Massachusetts General Hospital (MGH), our subjects are more likely to be White $(91.3 \%$ in this cohort vs. $76 \%$ in the $\mathrm{MGH}$ outpatient specialty care population), not Hispanic or Latino $(96.64 \%$ in this cohort vs. $91.2 \%$ in the $\mathrm{MGH}$ outpatient specialty care population) and female $(75.8 \%$ in this cohort vs. $51.8 \%$ in the MGH outpatient specialty care population) (27).

For 98 of the subjects, we had at least one follow-up study visit, obtained at least 9 months after the enrollment visit. In this subset, $76.5 \%$ of subjects $(75 / 98)$ had dystonia restricted to the neck. In $23.5 \%$ of subjects with follow-up (23/98), dystonia spread from the neck to adjacent body regions, resulting in segmental dystonia (Table 1). One subject developed multifocal dystonia, affecting both hands as well as upper and lower facial muscles; one subject developed generalized dystonia; two individuals first developed dystonia in an adjacent body region (spasmodic dysphonia or lower face) with subsequent extension 
to the neck. Using a Fisher exact test, there was no significant correlation between dystonia spread and family history of dystonia, tremor, Parkinson's Disease, and/or myoclonus ( $p$ $=0.729$ ).

\section{Family History}

Analysis of our cohort's first and second-degree relatives revealed that $47.0 \%(70 / 149)$ had a positive family history of movement disorders (dystonia, tremor, Parkinson's Disease, and/or myoclonus), $45.0 \%$ (67/149) had a negative family history, and $8.0 \%$ had a possible/unknown family history (12/149). The 67 subjects with a positive family history of a movement disorder were tested for presence of the DYT1 mutation as this has been reported to result in cervical dystonia in rare cases and is a common cause of familial disease (28).

\section{Socioeconomics}

All subjects were covered by a health insurance plan, with $62.4 \%$ having private insurance $(93 / 149)$ and $37.6 \%$ having publicly funded insurance (56/149, Medicare, or Medicaid). A higher proportion of males had private insurance compared to females $(p=0.01)$. In the Commonwealth of Massachusetts, the Center for Health Information and Analysis (CHIA) conducted a Health Insurance Survey in 2019 and found that $92 \%$ of residents had health insurance coverage for the entire year. Of those with insurance, $64.4 \%$ had private insurance and $31.2 \%$ had publicly funded insurance (Medicare or Medicaid). Based on the chi squared goodness of fit model, there is no statistically significant difference ( $p=0.09$ ) between our insurance rates in our cohort and that of the state. An additional 3.1\% of state residents were covered by private, non-group coverage plans and none of these residents were represented in our cohort. Median household income was $\$ 89,440$ (IQR $=65,476-110,025)$. Median miles from the clinic was 35.65 (IQR 13.9-56.3). In our cohort, the median for time to diagnosis (age at diagnosis-the age at onset) was 10 years $(\mathrm{IQR}=4-8)$. We found there was no correlation between time to diagnosis and race, public vs. private insurance, miles to the clinic, nor median household income.

\section{Dystonia Rating Scale Scores}

At baseline exam, data from 147 subjects revealed a mean score of 4.6 on the Burke Fahn Marsden ( $\mathrm{SD}=2.2$ ), 144 subjects had a mean score of $6.1(\mathrm{SD}=2.2)$ on the Tsui, and 140 subjects had a mean score of $16.9(\mathrm{SD}=4.9)$ on the TWSTRS severity scale. At the most recent exam, data from 102 subjects revealed a mean score of 4.5 on the Burke-Fahn-Marsden ( $\mathrm{SD}=5.1)$, a mean score of 5.7 ( $\mathrm{SD}=2.5)$ on the Tsui, and a mean score of $14.8(\mathrm{SD}=6.3)$ on the TWSTRS severity scale. There were no differences in dystonia severity scores between the sexes when we take into account 95 subjects with all three movement scores on baseline exam and at most recent exam (Table 2).

\section{Mood and Quality of Life}

Of the 50 subjects who completed the non-motor scales, 6 $(12.0 \%)$ were male and $44(88.0 \%)$ were female. BAI revealed a mean anxiety score of $7.2( \pm 6.4)$, indicating minimal anxiety (Table 3). The distribution of BAI scores revealed 68\% (34/50)
TABLE 2 | Motor rating scale scores.

\begin{tabular}{lcccc}
\hline & Total $(\boldsymbol{n}=\mathbf{9 5})$ & Male $(\boldsymbol{n}=\mathbf{2 0})$ & Female $(\boldsymbol{n}=\mathbf{7 5})$ & $\boldsymbol{p}$-value \\
\hline $\begin{array}{l}\text { BFM V0, Mean } \\
\text { (SD) }\end{array}$ & $4.68(1.87)$ & $4.9(1.80)$ & $4.63(1.90)$ & 0.556 \\
$\begin{array}{l}\text { BFM VF, Mean } \\
\text { (SD) }\end{array}$ & $3.89(2.21)$ & $4.53(1.87)$ & $3.72(2.27)$ & 0.112 \\
$\begin{array}{l}\text { TSUI V0, Median } \\
\text { (IQR) }\end{array}$ & $6(5-8)$ & $6(6-8)$ & $6(5-8)$ & 0.596 \\
$\begin{array}{l}\text { TSUI VF, Median } \\
\text { (IQR) }\end{array}$ & $6(4-7)$ & $6.5(4.5-7.5)$ & $6(4-7)$ & 0.224 \\
$\begin{array}{l}\text { TWSTRS V0, } \\
\text { Median (IQR) }\end{array}$ & $18(16-20)$ & $19(17.5-21)$ & $18(15-20)$ & 0.374 \\
TWSTRS VF, & $15(10-20)$ & $16(10.5-20.5)$ & $15(10-19)$ & 0.654 \\
\begin{tabular}{l} 
Median (IQR) \\
\hline
\end{tabular} & & & & \\
\hline
\end{tabular}

with minimal anxiety, $16 \%(8 / 50)$ with mild anxiety, and $16 \%$ $(8 / 50)$ with moderate anxiety. BDI revealed a mean depression score of $7.30( \pm 7.6, n=50)$, indicating minimal depression. The distribution of BDI scores revealed 86\% (43/50) with minimal depression, 6\% (3/50) with mild depression, 6\% (3/50) with moderate depression, and $2 \%(1 / 50)$ with severe depression. Those with severe scores on the BDI were referred to his/her clinical neurologist and offered resources for support. There was no correlation between BAI or BDI with CD severity at baseline or the most recent exam based on TWSTRS (severity), BFM, or TSUI scores. The only SF-36 subscales to be associated with CD severity were physical functioning $(p=0.040)$ pain $(p=0.008)$ and general health $(p=0.014)$ at baseline using the TWSTRS severity scale. Upon further examination, the participants who completed the BDI and BAI scales had statistically better BFM, TWSTRS and TSUI movement scores at their most recent exam than those who did not complete the mood scales (BFM $p=$ 0.03 , TWSTRS $p=0.02$, TSUI $p=0.03$ ). Furthermore, we found that patients who completed the BDI and BAI were more likely to appear for their regular botulinum toxin injection visits $(p<0.0001)$.

\section{Treatment}

We closed the study on December 31,2019. At that time point, most subjects were being treated regularly with botulinum toxin injections using electromyographic guidance $(75 \%, 112 / 149)$. Many who underwent botulinum toxin injections were doing so quarterly $(46.97 \%, 70 / 149)$ with others either choosing to undergo injections less frequently $(16.78 \%, 25 / 149)$ or changing providers for their treatment due to insurance requirements or travel distance $(11.41 \%, 17 / 149)$. Of the 37 subjects who did not get regular treatment with botulinum toxin, 12 (8.05\%) had never tried it or felt it did not work, and 17 (11.41\%) found that the costs and discomforts of treatment with botulinum toxin were not worth the benefit. Eight of the 37 (5.37\%) had either died or faced other serious medical conditions (not associated with our study or their dystonia) that impeded access to regular botulinum toxin injections. Before these circumstances arose for the eight subjects, four had been receiving quarterly injections, one was stretching their injections, another had switched providers but continued 
TABLE 3 | Non-motor rating scale scores.

\begin{tabular}{lccc}
\hline & Total $(\boldsymbol{n}=\mathbf{5 0})$ & Male $(\boldsymbol{n}=\mathbf{6})$ & Female $(\boldsymbol{n}=\mathbf{4 4})$ \\
\hline $\begin{array}{l}\text { Beck Anxiety } \\
\text { Inventory }(n=50)\end{array}$ & $7.2 \pm 6.4$ & $2.86 \pm 3.29$ & $7.88 \pm 6.58$ \\
$\begin{array}{l}\text { Beck Depression } \\
\text { Index II }(n=50)\end{array}$ & $7.3 \pm 7.6$ & $5 \pm 2.94$ & $7.67 \pm 8.05$ \\
\hline SF-36 & Total $(\boldsymbol{n}=\mathbf{4 9})$ & Male $(\boldsymbol{n}=\mathbf{6})$ & Female $(\boldsymbol{n}=\mathbf{4 3})$ \\
\hline $\begin{array}{l}\text { Physical } \\
\text { functioning }\end{array}$ & $69.3 \pm 25.4$ & $82.14 \pm 14.96$ & $67.14 \pm 26.30$ \\
$\begin{array}{l}\text { Role limitations } \\
\text { due to physical }\end{array}$ & $54.3 \pm 44.1$ & $78.57 \pm 36.60$ & $50.30 \pm 44.39$ \\
health & & & \\
$\begin{array}{l}\text { Role limitations } \\
\text { due to emotional } \\
\text { problems }\end{array}$ & $72.4 \pm 38.1$ & $100 \pm 0$ & $67.86 \pm 39.37$ \\
Energy/fatigue & $54.5 \pm 20.9$ & $68.57 \pm 14.06$ & $52.11 \pm 21.03$ \\
$\begin{array}{l}\text { Emotional } \\
\text { well-being }\end{array}$ & $75.6 \pm 17.8$ & $82.85 \pm 12.59$ & $74.43 \pm 18.35$ \\
$\begin{array}{l}\text { Social functioning } \\
\text { Pain }\end{array}$ & $74.7 \pm 21.6$ & $83.93 \pm 21.30$ & $73.21 \pm 21.49$ \\
General health & $63.9 \pm 20.1$ & $67.86 \pm 15.64$ & $63.21 \pm 20.82$ \\
\hline All patients were & $66.0 \pm 22.2$ & $67.14 \pm 17.99$ & $65.83 \pm 23.03$ \\
\hline & & & \\
\hline
\end{tabular}

All patients were receiving botulinum toxin injection.

27 patients were on oral medications.

9 patients were on antidepressants.

treatment, and two had stopped their injections altogether. Women were more likely to continue receiving botulinum toxin than men $(\mathrm{p}=0.049)$. Based on the Wilcoxon signed-rank test for matched pairs, there was a statistically significant difference in baseline vs. final movement scores (BFM- $p=0.0001$, TSUI$p=0.0027$, TWSTRS $-p=0.0009, n=75$ ) in women who received botulinum toxin injections but not in men, indicating a measurable benefit of long-term treatment for women.

In addition to interval treatment with botulinum toxin, daily oral pharmacologic treatment was used in some subjects to treat dystonia or depression (Table 1). While 59.1\% (88/149) were not on any medications to alleviate dystonia, $19.5 \%(29 / 149)$ were treated with benzodiazepines, $4.7 \%$ (7/149) were treated with skeletal muscle relaxants, $1.3 \%(2 / 149)$ were treated with propranolol to alleviate a concomitant tremor, $0.7 \%(1 / 149)$ was on primidone to alleviate a tremor, $0.67 \%$ (1/149) was on an alpha-adrenergic agonist, and $11.4 \%$ (17/149) were on two or more medications to alleviate dystonia. In addition, $16.8 \%(25 / 149)$ were under treatment for depression. In those treated for depression, $56.0 \%(14 / 25)$ were prescribed selective serotonin reuptake inhibitors, $20.0 \%(5 / 25)$ were prescribed selective norepinephrine reuptake inhibitors, 20.0\% (5/25) were prescribed tricyclics, and lastly one subject was prescribed a dopamine reuptake inhibitor $4.0 \%(1 / 25)$.

Furthermore, $5.4 \%$ (8/149) were treated with deep brain stimulation (DBS) due to minimal or suboptimal response to treatment with botulinum toxin injections and oral medications. The use of DBS treatment was not significantly correlated with the severity of a subject's TWSTRS severity score at baseline or with an incidence of dystonia spread. In all eight subjects, the
DBS targeted the globus pallidus interna (GPi). Pre and post DBS scores were available for four subjects, whose relief ranged from 2 to 4 points on the TWSTRS motor scale. Albeit a small sample size, six of the subjects no longer receive botulinum toxin injections and have found substantial relief of their symptoms with DBS alone.

\section{DISCUSSION}

In this cohort of 149 patients diagnosed to have isolated dystonia, there appear to be gender differences in both the prevalence and age of onset of the disease. We found a 3-fold higher incidence in women than in men, consistent with previous reports $(29,30)$. Interestingly, we found a significant difference between genders in the mean age of onset, with men displaying symptoms nearly 7 years earlier than women. While our overall age of onset does align with other smaller studies, indicating that CD is an adultonset disease most commonly occurring around ages 40-45, we believe that this is the first report to identify a significantly younger age of onset in affected men. It is unclear whether these sex differences are the result of our relatively small sample size or indicative of a genetic predisposition/vulnerability that is specific to men with cervical dystonia. However, we did not see a sex difference in those who had a family history of movement disorders, arguing against a clear genetic predisposition to the development of CD in men.

This study is one of the first to look into barriers to care within cervical dystonia. We identified a significant range of values (nearly 50 years) and distribution (tailing to the right) in our cohort's median time to diagnosis 10 years. This suggests a disparity in access to healthcare and/or access to physicians familiar with cervical dystonia that is exaggerated in a portion of the cohort. The cohort's median time to diagnosis, 10 years (IQR $=4-18$ ), was nearly double that reported in an Australian study of 50 subjects with CD and three times that reported in a US study $(16,31)$. We did not find a significant interaction between time to diagnosis and race/ethnicity, insurance status, median household income, or miles from the clinic. Upon further investigation on the $10-15 \%$ at the extreme end of the distribution spectrum, there does not seem to be any statistically noticeable pattern that distinguishes them from the larger cohort based on the data we collected, including race, public vs. private insurance, miles to the clinic, and median household income.

In those who received a diagnosis of cervical dystonia and had access to treatment, $\sim 11 \%$ felt that botulinum toxin was not worth the pain or cost and $8 \%$ had no benefit or never tried it. Botulinum toxin is one of the main treatment strategies for $\mathrm{CD}$, and the majority of this cohort was receiving injections regularly ( $47 \%$ quarterly, $17 \%$ stretching their injections longer) and finding measurable benefits from the treatment. There was a significant reduction in all three measures of dystonia severity (BFM, Tsui, and TWSTRS) from baseline to the most recent exam in women receiving botulinum toxin injections but not in the men. Similar to the sex difference we found in age of onset, this finding may be due to a small sample of male participants or indicative of sex-based differences in response to treatment. 
In our sample of 149 subjects, $5.4 \%$ opted for treatment with deep brain stimulation (DBS). While case series have shown its effectiveness in $\mathrm{CD}$, a multi-center prospective study analyzing its efficacy, including patient-reported outcome measures, may help determine which patients would most benefit (32).

For those who discontinued their care at the clinic, $57.9 \%$ did not cite a complete lack of benefit from botulinum toxin but either found that there was an insufficient pharma-economic benefit or an excessive travel burden involved. These results are in line with previous reports, which cited that reasons for discontinuation of care include high cost, suboptimal response to or side effects from botulinum toxin, and excessive travel burden $(7,17)$. Males were more likely to discontinue their botulinum toxin care, which may be associated with the lack of a significant reduction in their objective measures of dystonia severity. Although the current study attempted to further understand barriers to care by measuring socio-economic status (SES) through city median household income and measuring miles from the clinic, there was no direct correlation with care outcomes.

Previous studies have demonstrated the coexistence of severe depression and anxiety with isolated cervical dystonia (14). In contrast, our findings indicate that although depression and anxiety are present among these patients, their scores fall into a minimal range. Additionally, our average $\mathrm{BAI}$ and BDI scores were slightly lower than those presented in a cohort of $255 \mathrm{CD}$ subjects (12). While the BDI and BAI have not been validated for dystonia, they have been used in previous studies of dystonia cohorts $(2,12)$. All of the patients who completed the nonmotor scales were receiving regular botulinum toxin injections. Evidence suggests that the severity of depressive symptoms decreases with the successful use of botulinum toxin therapy for CD (33). This may explain the lower rate of acute, untreated depression and anxiety in our cohort. However, additional studies to both validate the use of the BDI and BAI in dystonia subjects, and determine appropriate cutoff scores to identify mood disorders are required.

In our cohort, the SF-36 subscales that showed a significant correlation with CD severity (as measured by the TWSTRS) were physical functioning, pain, and general health. To our knowledge, this is the first report to demonstrate a correlation between the TWSTRS severity score, an objective measure of motor dysfunction, and patient-reported physical function, pain and general health perception. Taken together, our participantreported data indicate that $\mathrm{CD}$ motor severity correlates with reduced quality of life and daily physical function, but not with underlying depression or anxiety. SF-36 scores for the patients with $C D$ were significantly lower (worse) than normative values in the US population in the domains of physical functioning, role limitations due to physical health, social functioning, and pain $(26,34)$. These findings suggest that the highest burden from $C D$ on quality of life is physical and social, rather than mental or emotional. A subsequent study is needed to better understand the psychiatric profile of cervical dystonia, and this should include asking subjects to complete the questionnaires during every stage of the study to control for confounding variables such as treatment effectiveness.
In summary, this study presents a cohort of $\mathrm{CD}$ patients who have a significantly younger age of onset in males, and a high prevalence of women and White non-Hispanic individuals. Our study found no significant psychiatric associations with mood disorders, such as anxiety or depression, which have been reported in other studies of CD patients. Additionally, our findings suggest that the $\mathrm{CD}$ population does experience barriers to care, which can be reflected in their treatment dropout rates and time-to-diagnosis, the latter of which could average well above 10 years. A future study on the natural history of cervical dystonia and barriers to care should include using more comprehensive indicators of socio-economic status, such as a subject's self-reported household income, educational status, and travel time rather than the distance from the clinic. Additionally, future research should be conducted in a larger, more racial/ethnic diverse cohort.

\section{LIMITATIONS}

Our cohort is overwhelmingly White and non-Hispanic/Latino. This could be interpreted in multiple ways, including: an artefactual finding due to relatively small sample size; an accurate indicator of the predominance of cervical dystonia in White non-Hispanic populations; or the result of reporting from a highly specialized neurologic clinic that under-serves minorities, which is reflected in their lack of participation in research at academic healthcare centers. A better understanding of the epidemiology and barriers to care within the cervical dystonia population is needed, but these results do align with a multiethnic American study that cited a higher prevalence of $\mathrm{CD}$ in White individuals (5).

Regarding the etiology of $\mathrm{CD}$ in this cohort, all subjects with a positive family history of movement disorder were screened and found to be negative for the DYT1 mutation. While genetic causes of isolated CD are thought to be rare, it is possible that some members of our cohort carry other dystonia-causing genes, such as DYT25 or DYT6, for which we did not screen.

The findings presented on mood and quality of life suggest that the highest burden from $\mathrm{CD}$ on quality of life is physical and social, rather than mental or emotional. However, these findings may be confounded by selection bias, because only one-third of the cohort completed psychiatric and QoL questionnaires, and these forms were dispensed at follow-up visits to subjects who continued with treatment. Furthermore, those who are psychiatrically well may be more likely to actively participate in research than those with more mental/emotional burden from $\mathrm{CD}$ or other diseases (25). Our study is limited to the patients who were able to start and continue treatment at our clinic, and specifically those who were willing and able to participate in research before or after their medical appointments. Additionally, not all subjects were tracked on the same interval schedule due to their personal availability. A subsequent study is needed to better understand the psychiatric profile of cervical dystonia, and this should include asking subjects to complete the questionnaires during every stage 
of the study to control for confounding variables such as treatment effectiveness.

\section{DATA AVAILABILITY STATEMENT}

The raw data supporting the conclusions of this article will be made available by the authors, without undue reservation.

\section{ETHICS STATEMENT}

The studies involving human participants were reviewed and approved by Mass General Brigham Human Research Committee. The patients/participants provided their written informed consent to participate in this study.

\section{AUTHOR CONTRIBUTIONS}

MS, PA, SC, MD-H, and NS: conception, organization, and execution of research project, design, execution, and review and critique of statistical analysis, and writing of the first draft and review and critique of the manuscript. JK, XA, TF, PA, LC, LP, and LO: execution of the research project and review and critique of the statistical analysis and manuscript. TM-B, EP,

\section{REFERENCES}

1. Ortiz RM, Scheperjans F, Mertsalmi T, Pekkonen E. Comorbidity and retirement in cervical dystonia. J Neurol. (2019) 266:221623. doi: 10.1007/s00415-019-09402-0

2. Novaretti N, Cunha ALN, Bezerra TC, Pena Pereira MA, de Oliveira DS, Macruz Brito MMC, et al. The prevalence and correlation of non-motor symptoms in adult patients with idiopathic focal and segmental dystonia. Tremor Other Hyperkinet Mov. (2019) 9:596. doi: 10.5334/tohm.466

3. Claypool DW, Duane DD, Ilstrup DM, Melton LJ. Epidemiology and outcome of cervical dystonia (spasmodic torticollis) in Rochester, Minnesota. Mov Disord. (1995) 10:608-14. doi: 10.1002/mds.870100513

4. Epidemiological Study of Dystonia in Europe (ESDE) Collaborative Group. A prevalence study of primary dystonia in eight European countries. J Neurol. (2000) 247:787-92. doi: 10.1007/s004150070094

5. Marras C, van den Eeden SK, Fross RD, Benedict-Albers KS, Klingman J, Leimpeter $\mathrm{AD}$, et al. Minimum incidence of primary cervical dystonia in a multiethnic health care population. Neurology. (2007) 69:67680. doi: 10.1212/01.wnl.0000267425.51598.c9

6. Nakashima K, Kusumi M, Inoue Y, Takahashi K. Prevalence of focal dystonias in the western area of Tottori prefecture in Japan. Mov Disord. (1995) 10:440-3. doi: 10.1002/mds.870100406

7. Comella C, Bhatia K. An international survey of patients with cervical dystonia. J Neurol. (2015) 262:837-48. doi: 10.1007/s00415-014-7586-2

8. Berman BD, Groth CL, Sillau SH, Pirio Richardson S, Norris SA, Junker J, et al. Risk of spread in adult-onset isolated focal dystonia: a prospective international cohort study. J Neurol Neurosurg Psychiatry. (2020) 91:31420. doi: 10.1136/jnnp-2019-321794

9. Martino D, Berardelli A, Abbruzzese G, Bentivoglio AR, Esposito M, Fabbrini G, et al. Age at onset and symptom spread in primary adultonset blepharospasm and cervical dystonia. Mov Disord. (2012) 27:144750. doi: $10.1002 / \mathrm{mds} .25088$

10. Jahanshahi M, Marion MH, Marsden CD. Natural history of adult-onset idiopathic torticollis. Arch Neurol. (1990) 47:54852. doi: 10.1001/archneur.1990.00530050070014

11. Pekmezovic T, Svetel M, Ivanovic N, Dragasevic N, Petrovic I, Tepavcevic DK, et al. Quality of life in patients with focal dystonia. Clin Neurol Neurosurg. (2009) 111:161-4. doi: 10.1016/j.clineuro.2008.09.023 and CS: conception, organization, and execution of the research project and review and critique of the statistical analysis and manuscript. GA: organization and execution of the research project and review and critique of the statistical analysis and manuscript. All authors contributed to the article and approved the submitted version.

\section{FUNDING}

NS was supported by NIH NINDS P01 NS087997. NS has received honoraria from John Wiley Publishing for serving as editor-in-chief for Brain and Behavior. LO was supported by NIH NINDS P01 NS087997. CS has sat on a scientific advisory board for Xenon Pharmaceuticals and received research funding from Sanofi-Genzyme for a study of video oculography in lateonset GM2 gangliosidosis. He has received financial support from Sanofi-Genzyme, Biogen and Biohaven for the conduct of clinical trials. MD-H has received research funding from the Tourette Association of America. She has also received financial support from Retrophin for the conduct of clinical trials. She has received honoraria from NORD for assistance on report for ADCY5related dyskinesia. MS has no relevant or material financial interests that relate to the research described in this paper.

12. Berman BD, Junker J, Shelton E, Sillau SH, Jinnah HA, Perlmutter JS, et al. Psychiatric associations of adult-onset focal dystonia phenotypes. $J$ Neurol Neurosurg Psychiatry. (2017) 88:595-602. doi: 10.1136/jnnp-2016315461

13. van den Dool J, Tijssen MA, Koelman JH, Engelbert RH, Visser B. Determinants of disability in cervical dystonia. Parkinsonism Relat Disord. (2016) 32:48-53. doi: 10.1016/j.parkreldis.2016.08.014

14. Foley JA, Vinke RS, Limousin P, Cipolotti L. Relationship of cognitive function to motor symptoms and mood disorders in patients with isolated dystonia. Cogn Behav Neurol. (2017) 30:16-22. doi: 10.1097/WNN.00000000000 00117

15. Jankovic J. Botulinum toxin therapy for cervical dystonia. Neurotox Res. (2006) 9:145-8. doi: 10.1007/BF03033933

16. Jog M, Chouinard S, Hobson D, Grimes D, Chen R, Bhogal M, et al. Causes for treatment delays in dystonia and hemifacial spasm: a Canadian survey. Can J Neurol Sci. (2011) 38:704-11. doi: 10.1017/S0317167100012270

17. Bertram KL, Williams DR. Delays to the diagnosis of cervical dystonia. J Clin Neurosci. (2016) 25:62-4. doi: 10.1016/j.jocn.2015.05.054

18. Tiderington E, Goodman EM, Rosen AR, Hapner ER, Johns MM 3rd, Evatt ML. How long does it take to diagnose cervical dystonia? J Neurol Sci. (2013) 335:72-4. doi: 10.1016/j.jns.2013.08.028

19. Gill CE, Manus ND, Pelster MW, Cook JA, Title W, Molinari $\mathrm{AL}$, et al. Continuation of long-term care for cervical dystonia at an academic movement disorders clinic. Toxins. (2013) 5:776-83. doi: 10.3390/toxins5040776

20. Albanese A, Bhatia K, Bressman SB, Delong MR, Fahn S, Fung VS, et al. Phenomenology and classification of dystonia: a consensus update. Mov Disord. (2013) 28:863-73. doi: 10.1002/mds.25475

21. Bressman SB, Warner TT, Almasy L, Uitti RJ, Greene PE, Heiman GA, et al. Exclusion of the DYT1 locus in familial torticollis. Ann Neurol. (1996) 40:681-4. doi: 10.1002/ana.410400421

22. Bressman SB, de Leon D, Brin MF, Risch N, Burke RE, Greene PE, et al. Idiopathic dystonia among Ashkenazi Jews: evidence for autosomal dominant inheritance. Ann Neurol. (1989) 26:612-20. doi: 10.1002/ana.410260505

23. Beck A, Steer R, Brown G. BDI-II: Beck Depression Inventory Manual. 2nd ed. San Antonio, TX: Psychological Corporation (1996).

24. Beck A, Steer R. BAI: Beck Anxiety Inventory Manual. San Antonio, TX: Psychological Corporation (1993). 
25. Massey DS, Tourangeau R. Where do we go from here? Nonresponse and social measurement. Ann Am Acad Polit Soc Sci. (2013) 645:22236. doi: 10.1177/0002716212464191

26. Ware, JE, Snow KK, Kosinski M, Gandek B, Health Survey Manual and Interpretation Guide. Boston, MA: The Health Institute, New England Medical Center (1993).

27. Mort E, Reilly S, Tull A, Kim T, Malin R. Annual Report on Equity in Health Care Quality 2016-2017. Boston, MA (2017).

28. Grundmann K, Laubis-Herrmann U, Bauer I, Dressler D, Vollmer-Haase J, Bauer P, et al. Frequency and phenotypic variability of the GAG deletion of the DYT1 gene in an unselected group of patients with dystonia. Arch Neurol. (2003) 60:1266-70. doi: 10.1001/archneur.60.9.1266

29. Wagle Shukla A, Brown R, Heese K, Jones J, Rodriguez RL, Malaty IM, et al. High rates of fatigue and sleep disturbances in dystonia. Int J Neurosci. (2016) 126:928-35. doi: 10.3109/00207454.2015.1085035

30. van Zandijcke M. Cervical dystonia (spasmodic torticollis). Some aspects of the natural history. Acta Neurol Belg. (1995) 95:210-5.

31. Taylor PN, Albrecht D, Scholz A, Gutierrez-Buey G, Lazarus JH, Dayan CM, et al. Global epidemiology of hyperthyroidism and hypothyroidism. Nat Rev Endocrinol. (2018) 14:301-16. doi: 10.1038/nrendo. 2018.18

32. Hung SW, Hamani C, Lozano AM, Poon YY, Piboolnurak P, Miyasaki $\mathrm{JM}$, et al. Long-term outcome of bilateral pallidal deep brain stimulation for primary cervical dystonia. Neurology. (2007) 68:457-9. doi: 10.1212/01.wnl.0000252932.71306.89

33. Müller J, Kemmler G, Wissel J, Schneider A, Voller B, Grossmann J, et al. The impact of blepharospasm and cervical dystonia onhealth-related quality of life and depression. J Neurol. (2002) 249:842-46. doi: 10.1007/s00415-002-0733-1

34. Mordin M, Masaquel C, Abbott C, Copley-Merriman C. Factors affecting the health-related quality of life of patients with cervical dystonia and impact of treatment with abobotulinumtoxinA (Dysport): results from a randomised, double-blind, placebo-controlled study. BMJ Open. (2014) 4:e005150. doi: 10.1136/bmjopen-2014-005150

Conflict of Interest: The authors declare that the research was conducted in the absence of any commercial or financial relationships that could be construed as a potential conflict of interest.

Copyright (C) 2020 Supnet, Acuna, Carr, Kristoper de Guzman, Al Qahtani, Multhaupt-Buell, Francoeur, Aldykiewicz, Alluri, Campion, Paul, Ozelius, Penney, Stephen, Dy-Hollins and Sharma. This is an open-access article distributed under the terms of the Creative Commons Attribution License (CC BY). The use, distribution or reproduction in other forums is permitted, provided the original author(s) and the copyright owner(s) are credited and that the original publication in this journal is cited, in accordance with accepted academic practice. No use, distribution or reproduction is permitted which does not comply with these terms. 